\title{
Multi-State Load Models for Distribution System Analysis
}

\author{
Kevin P. Schneider, Senior Member, IEEE, Jason C. Fuller, Member, IEEE, and
}

David P. Chassin, Senior Member, IEEE

\begin{abstract}
Recent work in the field of distribution system analysis has shown that the traditional method of peak load analysis is not adequate for the evaluation of emerging distribution system technologies. Voltage optimization, demand response, electric vehicle charging, and energy storage are examples of technologies with characteristics having daily, seasonal, and/or annual variations. In addition to the seasonal variations, emerging technologies such as demand response and plug-in electric vehicle charging have the potential to receive control signals that affects their energy consumption. To support time-series analysis over different time frames and to incorporate potential control signal inputs, detailed end-use load models that accurately represent loads under various conditions, and not just during the peak load period, are necessary. This paper will build on previous end-use load modeling work and outline the methods of general multi-state load models for distribution system analysis.
\end{abstract}

Index Terms-Distribution system analysis, forward-backward sweep method, load modeling, Newton-Raphson method, power modeling, power simulation, smart grid.

\section{INTRODUCTION}

$\mathbf{T}$ HE use of proper analytic tools is critical to ensure the proper design, deployment, and operation of modern electric power systems. This is especially true of the emerging generation of technologies such as voltage optimization, demand response, electric vehicle charging, and energy storage. Electric power system models can be divided into three fundamental areas for the purposes of analysis: generation, transmission/distribution, and end-use loads. To obtain the maximum benefit from the electricity infrastructure, it is necessary to fully address each of the three areas. This paper will focus on developing an approach to multi-state load models for use in distribution system analysis.

The first of the three fundamental model areas within an electric power system is the representation of generation. For a simple distribution system with a single source at the substation

Manuscript received October 24, 2010; revised January 20, 2011; accepted March 10, 2011. Date of publication May 05, 2011; date of current version October 21, 2011. This work was supported by the Pacific Northwest National Laboratory, which is operated by Battelle for the U.S. Department of Energy, under Contract DE-AC05-76RL01830. Paper no. TPWRS-00860-2010.

K. P. Schneider is with Pacific Northwest National Laboratory, Battelle Seattle Research Center, Seattle, WA 98109 USA (e-mail: kevin. schneider@pnl.gov).

J. C. Fuller and D. P. Chassin are with the Pacific Northwest National Laboratory, Richland, WA 99352 USA (e-mail: jason.fuller@pnl.gov; david.chassin@pnl.gov).

Digital Object Identifier 10.1109/TPWRS.2011.2132154 and no distributed generation, the substation transformer can be modeled as a balanced, or unbalanced, voltage source behind a three-phase impedance [1]. In a multi-source distribution system with distributed resources, such as wind turbines, the work presented by Samaan et al. [2] details how distributed generator models can be integrated into the IEEE Test Feeders [3], [4].

The second fundamental area focuses on the transport of power from the generators to the end-use loads via transmission and distribution systems. In general, the modeling of the transmission system is a simplified case of the distribution system. While transmission systems are well balanced and can be constructed with transposed lines, distribution systems are unbalanced systems where single and double phase laterals are common. Extensive work has been conducted to generate detailed models of the various distribution system components [1], [5]-[9]. The most common elements of a distribution system are the overhead lines and underground cables, both of which can be modeled using the well-established techniques presented by Carson in 1926 [5]. While Carson's work was not readily adopted when it was first presented in 1926, it has since become the standard method for modeling overhead lines and underground cables. Using this approach as a starting point, Carson's equations have been generalized and representations for the various distribution transformer connections, including single phase, three phase, split phase center-tapped, and the various regulator types have been developed [1]. Using the developed models of the various devices, Kersting then solved the power flow problem assuming time-invariant load models using a forward-backward sweeping solution method. While the forward-backward sweeping method is an efficient algorithm, it is not capable of analyzing weakly meshed or networked distribution systems. To analyze networked systems, Garcia et al. [6] and Araujo et al. [7] developed the Three-phase Current Inject Method (TCIM). The TCIM method has been extended to include ground resistance values so that neutral to earth voltages may be examined [8], [9].

It is clear that the first two fundamental areas of the electric power system, generation and transmission/distribution, have received significant study. However, end-use load modeling has not received the same level of attention. Currently, the most common method of end-use modeling is to consider the loads as time-invariant combinations of constant impedance, constant current, and constant power elements, referred to as a ZIP model [1]. The complexity of the ZIP model can be increased by connecting elements in unbalanced Delta or Wye combinations, or even combined to form motor models [3]. Despite the increased 
complexity, the load models are still time-invariant and represent only one load state. One method for introducing timevariant load models is to implement load profiles. Load profiles utilize the basic ZIP model, but the ratios and magnitudes of individual elements are allowed to change with respect to time. The use of load profiles is a common feature in commercial software [10]-[12], but they usually operate with a 15-min or 1-h time frame, which is much longer than the time constant of most end-use loads.

As part of the Western Electricity Coordinating Council (WECC) Load Modeling task force, there have been efforts to develop load models that represent the behavior of end-use loads in the sub-minute time scale. However, these efforts have focused primarily on modeling many small induction motors by aggregating them into a few large induction machines to model their impact on the stability of transmission systems [13]. Despite the significant improvements in model fidelity, the majority of distribution system end-use loads have characteristics that differ from those of a single large induction machines, so this approach remain only an interim solution while more detailed load models are developed.

One attempt to model distribution system end-use loads in detail was introduced in Guttromson et al. [14]. The work of [15] advanced the concept of using detailed physical models to represent the heating/cooling systems of single family residences. While this was an effective representation for a residential heating/cooling system in a single operating state, it did not fully account for the transitions between operating states. As a result, it was not a complete framework for modeling end-use loads. There still exists a need for an effective, multi-state distribution system end-use load model to accurately represent end-use load behavior across multiple time scales.

Development of multi-state load models is necessary to fully represent the behavior of the existing distribution system infrastructure and to evaluate the impact of emerging smart grid technologies. Technologies such as electric vehicle charging and demand response will force appliances and devices to transition between different operational states, each with unique behaviors. For example, the energy consumption of a clothes dryer can change when a demand response signal indicates a high price, possibly cycling the heating coils while the motor continues to run. To properly represent the behavior of end-use loads, time-variant multi-state end-use load models need to account for operations in multiple states, including the impacts of state transitions.

The rest of this paper is organized as follows: Section II discusses single state time-variant distribution system models and Section III introduces the concept of multi-state models. Section IV examines the impact of time-variant multi-state models on a single family residence, while Section V examines their impact on the IEEE 8500-node test system. Section VI contains the conclusions as well as plans for future work.

\section{Single-State Time-VARIANT LoAd Models}

Even the simplest distribution systems loads are time-variant because of the normal variations of the distribution system voltage. To account for the time-varying dependence on terminal voltage, two methods for modeling the voltage dependence of end-use loads have been developed: ZIP models [1] and physical models [15].

\section{A. ZIP Models}

ZIP models are two state models, energized and de-energized. When energized there is only a single operational state and the energy consumption can be determined using (1) for real power, (2) for reactive power, and (3) as a constraint [15]:

$$
\begin{aligned}
P_{i}= & {\left[\frac{\left|V_{a}^{2}\right|}{\left|V_{n}^{2}\right|} \cdot\left|S_{n}\right| \cdot Z_{\%} \cdot \cos \left(Z_{\theta}\right)+\frac{\left|V_{a}\right|}{\left|V_{n}\right|} \cdot\left|S_{n}\right| \cdot I_{\%}\right.} \\
& \left.\cdot \cos \left(I_{\theta}\right)+\left|S_{n}\right| \cdot P_{\%} \cdot \cos \left(P_{\theta}\right)\right] \\
Q_{i}= & {\left[\frac{\left|V_{a}^{2}\right|}{\left|V_{n}^{2}\right|} \cdot\left|S_{n}\right| \cdot Z_{\%} \cdot \sin \left(Z_{\theta}\right)+\frac{\left|V_{a}\right|}{\left|V_{n}\right|} \cdot\left|S_{n}\right| \cdot I_{\%}\right.} \\
& \left.\cdot \sin \left(I_{\theta}\right)+\left|S_{n}\right| \cdot P_{\%} \cdot \sin \left(P_{\theta}\right)\right] \\
100= & Z_{\%}+I_{\%}+P_{\%}
\end{aligned}
$$

where

$P_{i} \quad$ real power consumption of the $i$ th load;

$Q_{i} \quad$ reactive power consumption of the $i$ th load;

$V_{a} \quad$ actual terminal voltage;

$V n \quad$ nominal terminal voltage;

$S_{n} \quad$ apparent power consumption at nominal voltage;

$Z_{\%} \quad$ percent of load that is constant impedance;

$I_{\%} \quad$ percent of load that is constant current;

$P_{\%} \quad$ percent of load that is constant power;

$Z_{\theta} \quad$ phase angle of constant impedance component;

$I_{\theta} \quad$ phase angle of constant current component;

$P_{\theta} \quad$ phase angle of constant power component.

In a time-variant load representation, the coefficients of the ZIP model, $V_{\mathrm{n}}, S_{\mathrm{n}}, Z_{\%}, I_{\%}, P_{\%}, Z_{\theta}, I_{\theta}$, and $P_{\theta}$, remain constant, but the power consumption, $P_{i}$ and $Q_{i}$, of the $i$ th load varies with the actual terminal voltage, $V_{a}$. The ZIP model is similar to the polynomial representation used in many commercial software packages. In the polynomial representation of the ZIP load, the constant coefficient is equivalent to $P_{\%}$, the linear coefficient is equivalent to $I_{\%}$, and the quadratic coefficient is equivalent to $Z_{\%}$. The ZIP model only varies the power consumption as a function of actual terminal voltage, $V_{a}$.

In traditional distribution analysis, ZIP models are generally not developed for every individual load; instead, models are developed for load classes such as residential, commercial, and industrial. Every load within a given load class then uses the same ZIP values with the exception of the apparent power consumption at nominal voltage, $S_{n}$. The value of $S_{n}$ for each load may change at $1-\mathrm{h}$ intervals to generate a daily load profile at the feeder level. The use of similar ZIP values for each load class, which only change at 1-h intervals, is not able to represent coincidental load peaks that occur at the distribution level.

\section{B. Physical Models}

When the energy consumption of an end-use load is a function of variables other than terminal voltage, the use of a ZIP 
model is not adequate. This is true of any load with an external control system or an internal control loop. To illustrate this issue, the air conditioning system of a single family residence will be examined while in the cooling mode. As with the ZIP model, an air conditioning system is a two-state model (ON or OFF), but only has a single operational state.

Because a cooling system operates to maintain internal air temperature within a band, parameters such as near term history of operation, time of year, outside air temperature, building construction, and terminal voltage will impact the instantaneous power consumption, as well as the energy consumption. To examine these issues, a physical model of the cooling system and the structure of the building is constructed using an equivalent thermal parameter (ETP) model [15]-[19]. Because the ETP model has been shown to be an accurate representation of residential and small commercial building instantaneous power draw, as well as energy consumption, it will be used for the formulation of the physical model.

Fig. 1 is a diagram showing the heat flow for the ETP model of a single family residence, i.e., a house. While the heating/ cooling system can be one of any numerous types, for the purposes of this paper, it is assumed that the system is a heat pump in the cooling mode. In addition to the heat removal of the heat pump while cooling and the heat gain through the building exterior, there are two additional significant flows of heat within a house: incident solar radiation and internal gains from waste heat generated by end-use loads. These sources and sinks of heat constitute the total heat energy exchange in the house. This flow of heat is then divided between the air in the house and the mass of the house, i.e., walls and furniture. A portion of the incident solar energy shining through a window will heat the interior air of the house, while the remaining incident energy will be absorbed by the walls, floors, and furniture. The same division occurs with the waste heat from end-use loads. The internal air temperature of the house is thermally coupled to the internal mass temperature, and the internal air temperature is then thermally coupled to the outside air temperature through the thermal envelope of the house, where

$\begin{array}{ll}C_{\text {air }} & \text { air heat capacity }\left(\mathrm{Btu} /{ }^{\circ} \mathrm{F}\right) ; \\ C_{\text {mass }} & \text { mass heat capacity }\left(\mathrm{Btu} /{ }^{\circ} \mathrm{F}\right) ; \\ U A_{\text {env }} & \text { external gain/heat loss coefficient }\left(\mathrm{Btu} /{ }^{\circ} \mathrm{F}-\mathrm{h}\right) ; \\ U A_{\text {mass }} & \text { internal gain/heat loss coefficient }\left(\mathrm{Btu} /{ }^{\circ} \mathrm{F}-\mathrm{h}\right) ; \\ T_{\text {out }} & \text { air temperature outside the house }\left({ }^{\circ} \mathrm{F}\right) ; \\ T_{\text {air }} & \text { air temperature inside the house }\left({ }^{\circ} \mathrm{F}\right) ; \\ T_{\text {mass }} & \text { mass temperature inside the house }\left({ }^{\circ} \mathrm{F}\right) ; \\ T_{\text {set }} & \text { temperature set points of } \mathrm{HVAC} \text { system }\left({ }^{\circ} \mathrm{F}\right) ; \\ Q_{\text {air }} & \text { heat rate to house air }(\mathrm{Btu} / \mathrm{h}) ; \\ Q_{\text {gains }} & \text { heat rate from appliance waste heat }(\mathrm{Btu} / \mathrm{h}) ; \\ Q_{\text {hvac }} & \text { heat rate from } \mathrm{HVAC} \text { system }(\mathrm{Btu} / \mathrm{h}) ; \\ Q_{\text {mass }} & \text { heat rate to house mass }(\mathrm{Btu} / \mathrm{h}) ; \\ Q_{\text {solar }} & \text { heat rate from solar gains }(\mathrm{Btu} / \mathrm{h}) .\end{array}$

Equation (4) is the second order differential equation that describes the heat flows shown in Fig. 1 [18]. Its solution determines the time-varying temperature of the house, both air and

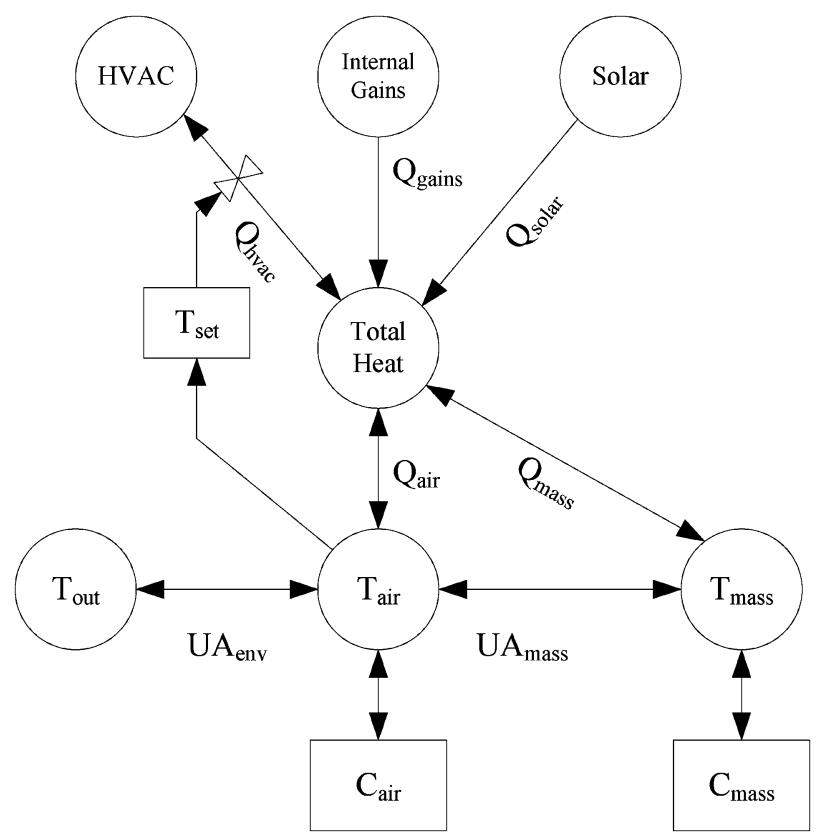

Fig. 1. ETP model of a residential heating/cooling system.

mass, given the thermal inputs. With the inside air temperature, $T_{a i r}$, known, the thermal behavior of the heat pump system in response to the defined thermostatic set point, $T_{\text {set }}$, can be determined:

$$
a \frac{d^{2} T_{a i r}}{d t^{2}}+b \frac{d T_{a i r}}{d t}+c T_{a i r}=d
$$

where

$$
\begin{aligned}
a & =\frac{C_{\text {mass }} \cdot C_{\text {air }}}{U A_{\text {mass }}} \\
b & =\frac{C_{\text {mass }} \cdot\left(U A_{\text {env }}+U A_{\text {mass }}\right)}{U A_{\text {mass }}}+C_{\text {air }} \\
c & =U A_{\text {env }} \\
d & =Q_{\text {mass }}+Q_{\text {air }}+\left(U A_{\text {env }} \cdot T_{\text {out }}\right) .
\end{aligned}
$$

With the temperature of the house known from (4) and the occupant-controlled set point fixed, the operation of the cooling system can be determined. Based on these values, the cooling system will operate long enough to remove the heat necessary to maintain the inside air temperature, $T_{a i r}$, within the desired range. The electrical input energy to the motor, $S_{c o m p-m o t o r}$, necessary to provide the thermal heat energy is a function of two elements: the heat flow through the cooling unit, $Q_{h v a c}$, and the electrical losses of the compressor motor, $S_{\text {losses }}$, as shown in (5) $[15]-[21]$ :

$$
S_{\text {comp-motor }}=\left[Q_{\text {hvac }}\left(T_{\text {out }}, V_{T}, C O P\right)+S_{\text {losees }}\left(V_{T}\right)\right] .
$$

The coefficient of performance $(C O P)$ is a scalar value that relates the cooling rate of the heat pump unit to the mechanical power delivered by the compressor as a function of temperature and operation time. A higher value of COP indicates less electrical power is necessary to remove a given amount of heat from the air. $V_{T}$ is the terminal voltage of the system compressor 
motor. Additionally, it should be noted that $Q_{h v a c}$ is expressed in terms of British thermal units (Btu) consistent with the conventions of the heating/cooling industry in the United States and the derivation of the ETP model of [15]-[19], while $S_{\text {losses }}$ is expressed in SI units. As a result, the two terms of (5) must be converted using the conversion of $1.0 \mathrm{Btu} / \mathrm{h}=0.2931 \mathrm{~W}$.

Because both of the elements of (5) are voltage dependent, changes in line voltage will cause a change in power consumption. The cooling system's heat removal rate, $Q_{\text {hvac }}$, can be solved using heat transfer equations based on the available mechanical torque of the compressor [15]-[19]. The motor losses, $S_{\text {losses }}$, can be determined using the traditional split phase motor model of [20] and [21]. When (5) is implemented in a time-series simulation, the result is a model that determines the energy consumption, both real and reactive, of the cooling system as a function of the outside air temperature, the inside air temperature, equipment parameters, terminal voltage, and occupant-controlled set point.

Unlike ZIP models that apply the same values to each load in a given load class, physical models are specific to each individual load. The values of physical models vary on a 1-s or 1-min basis to capture the true time-variant nature of the end-use load.

The previous example of a physical model has examined a heat pump in the cooling mode which is one of multiple operational states. Because of the design of heat pumps, their energy consumption varies according to their current operational state. To properly capture the energy consumption, it is necessary to construct a multi-state load model.

\section{Multi-State Time-VARIAnt LoAd ModelS}

A multi-state time-variant load model uses more than one state to describe the energy consumption of an end-use load. Each state is governed either by a ZIP model and/or a physical model, with transitions between states determined by either internal state transition rules or external signals. For example, a typical heat pump has four normal operating states: State 1 (off), State 2 (cooling), State 3 (heating-normal), and State 4 (heating-emergency). State 2 operates as described in the previous section, and State 3 follows a similar description but with different values that represent the change in the heating cycle, i.e., heat is added instead of removed. State 4 operates as State 3, except that the COP is 1.0 and the load is a ZIP model. There are other abnormal states such as "stalled compressor motor" or "low refrigerant charge", but they will not be examined in this paper. Additionally, there are numerous heat pump types and many differing thermostatic controllers that are commercially available, but this paper will discuss a "typical" design. Because a heat pump has two heat-flow configurations, the value of $T_{\text {set }}$ must be split into a heating set point, $T_{l o w}$, and a cooling set point, $T_{h i g h}$. These set points determine the mode of operation of the heat pump system at any given time: off, cooling, heating-normal, or heating-emergency, as shown in Fig. 2.

For a simple single state simulation, the heat pump system would be operating to either heat or cool the house, as discussed in the previous section. For a time-series simulation, the multistate model captures the transitions between states. While a heat pump system may not transition through all operational states in a single day, it is likely that it will transition through more

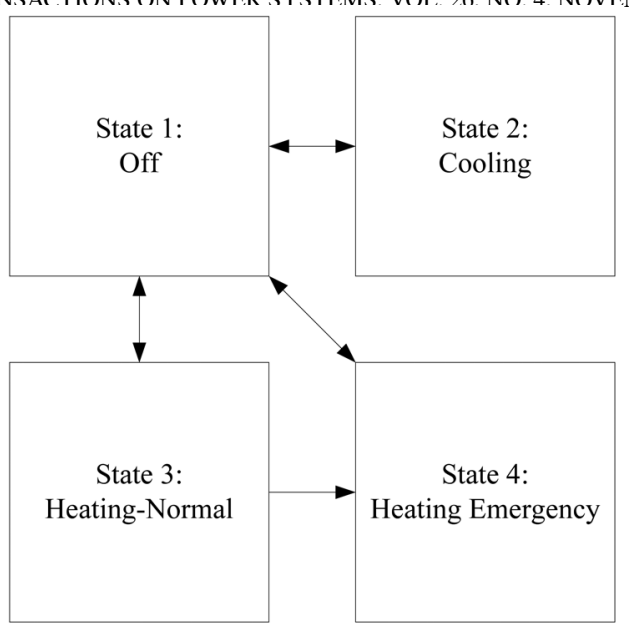

Fig. 2. Multi-state load model.

TABLE I

HeAT Pump State Transition Logic

\begin{tabular}{|c|c|c|}
\hline From State & To State & Transition Rule \\
\hline 1 & 2 & $T_{\text {air }}>\left(T_{\text {high }}+D B_{\text {high }}\right)$ \\
\hline 1 & 3 & $T_{\text {air }}<\left(T_{\text {low }}-D B_{\text {low }}\right)$ \\
\hline 1 & 4 & $T_{\text {air }}<\left(T_{\text {low }}-D B_{\text {low }}\right) \& T_{\text {out }}<T_{\text {aux }}$ \\
\hline 2 & 1 & $T_{\text {air }}<\left(T_{\text {high }}-D B_{\text {high }}\right)$ \\
\hline 3 & 1 & $T_{\text {air }}>\left(T_{\text {low }}+D B_{\text {low }}\right)$ \\
\hline 3 & 4 & $T_{\text {out }}<T_{\text {aux }}$ \\
\hline 4 & 1 & $T_{\text {air }}>\left(T_{\text {low }}+D B_{\text {low }}\right)$ \\
\hline
\end{tabular}

than one state in any given day. For example, on a mild autumn night, the heat pump may operate to heat the house, then as the sun heats the house during the day, it may be necessary to switch to cooling.

To be in States 2, 3, or 4, the heat pump unit must be turned "on" with defined set points, both occupant-controlled and internal. The occupant-controlled set points are $T_{\text {high }}$ and $T_{\text {low }}$. If the internal air temperature $T_{\text {air }}$ rises above $T_{\text {high }}$ plus a dead band, $D B_{\text {high }}$, then the heat pump will start cooling. If $T_{\text {air }}$ decreases below $T_{\text {low }}$ minus a dead band, $D B_{\text {low }}$, then the heat pump will start heating normally. If $T_{\text {out }}$ decreases to a temperature, $T_{a u x}$, where the heat pump efficiency becomes too low to effectively heat the home, the system will start heating in the emergency state using resistive heating elements. In addition to the internal control parameters of $T_{a u x}$, the $D B_{\text {low }}$ and $D B_{\text {high }}$ are internal parameters that are not occupant-controlled, but are included to prevent the heat pump from cycling excessively. Table I gives the logic for the allowable state transitions shown in Fig. 2.

Each of the four discrete states of operation has a different set of characteristics that determine the instantaneous power consumption. In State 1, there is no power draw because the system is off. In States 2 and 3, there is an electric fan motor plus a compressor motor. Similar to State 3 , State 4 provides heating with an associated electric fan for ventilation but with the difference that heating is provided by resistive heating elements and not 
a heat pump. The instantaneous power draw of the four states shown in Fig. 2 is given by (6)-(9).

State 1: Off

$$
S_{H V A C}=0
$$

State 2: Cooling

$$
S_{H V A C}=S_{\text {fan-motor }}+S_{\text {comp-motor }}
$$

State 3: Heating-Normal

$$
S_{H V A C}=S_{\text {fan-motor }}+S_{\text {comp-motor }}
$$

State 4: Heating-Emergency

$$
S_{H V A C}=S_{\text {fan-motor }}+\frac{V_{T}^{2}}{R_{\text {elements }}}
$$

where

$$
S_{\text {fan-motor }} \text { apparent power of ventilation fan motor }
$$
(VA);

$S_{\text {comp-motor }}$ apparent power of compressor motor (VA);

$V_{T}$ terminal voltage of the heat pump unit $(\mathrm{V})$;

$R_{\text {elements }}$ resistance of the heating coil elements $(\Omega)$.

While the power consumption for States 2 and 3, given by (7) and (8), respectively, appear to be the same, there are different internal models for $Q_{h v a c}$, particularly with respect to the COPs. With the instantaneous power draw determined by (6)-(9), the time necessary to heat or cool the house to within the occupant-controlled set points is determined by the solution to (4). The result is that variations in temperature, voltage, and efficiency are translated into a variable duty cycle of the heat pump. This information can then be used to determine the instantaneous power demand and the energy consumption of the heat pump over time.

\section{Single House Analysis (CASe 1)}

In this section, the state transitions and the associated power consumption of the heat pump in a single family residence are examined over a 24-h time frame. The simulations are conducted using the GridLAB-D simulation environment [22]. A single house is examined during a cool winter day, with temperatures between $25^{\circ} \mathrm{F}$ and $40^{\circ} \mathrm{F}$. Table II shows the heating and cooling set points, $T_{\text {low }}$ and $T_{\text {high }}$, respectively, that are used in the simulation; these set points are assumed to be user programmed thermostatic set points. The set points in Table II are representative of a heat pump type HVAC system in operation during a weekday. The additional internal control parameters are $D B_{\text {low }}=D B_{\text {high }}=1^{\circ} \mathrm{F}$ and $T_{\text {aux }}=28^{\circ} \mathrm{F}$.

Fig. 3 shows the indoor air temperature of the house, $T_{a i r}$, along with the occupant-controlled set points $T_{l o w}$ and $T_{\text {high }}$, which are shown in Table II. Fig. 4 shows the various states of the heat pump, which correspond to the operations shown in Fig. 3, while Fig. 5 shows the apparent power consumption of the heat pump. The change in air temperature shown in Fig. 3
TABLE II

HEATING/COOLING SET POINTS

\begin{tabular}{|c|c|c|c|}
\hline From (Time) & To (Time) & $T_{\text {low }}\left({ }^{\circ} \mathrm{F}\right)$ & $T_{\text {high }}\left({ }^{\circ} \mathrm{F}\right)$ \\
\hline $0: 00$ & $6: 00$ & 60 & 85 \\
\hline $6: 01$ & $8: 00$ & 70 & 80 \\
\hline $8: 01$ & $16: 00$ & 60 & 85 \\
\hline $16: 01$ & $22: 00$ & 70 & 80 \\
\hline $22: 01$ & $0: 00$ & 60 & 85 \\
\hline
\end{tabular}

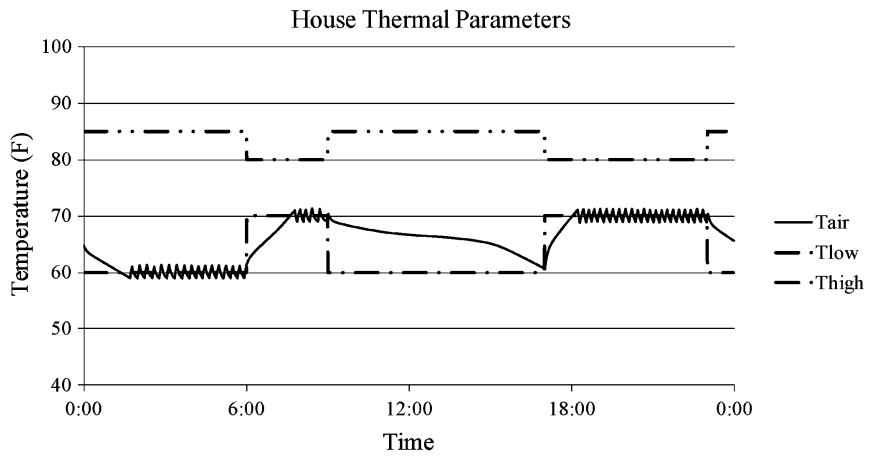

Fig. 3. House thermal parameters.

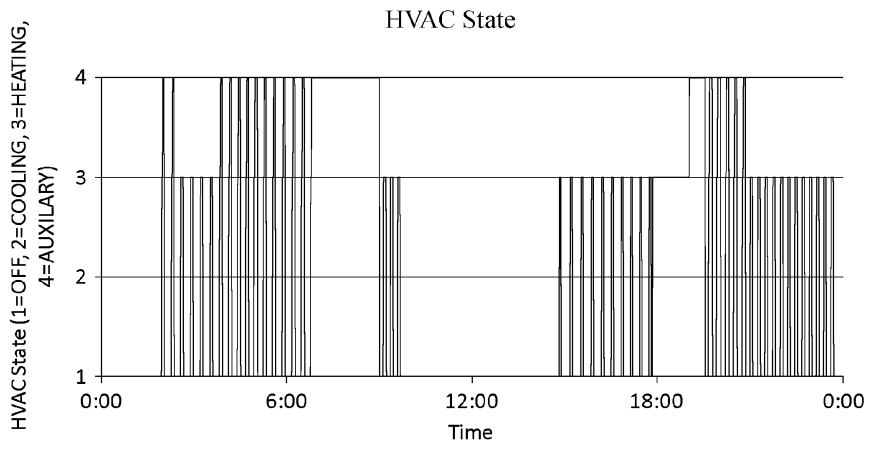

Fig. 4. Heat pump states.

can be attributed to operation of the heat pump in multiple operational states, as shown in Fig. 4. Comparing Fig. 4 with Fig. 5, the apparent power consumption in the different states can be seen; it is clear that various states draw significantly different amounts of power. Specifically, when heating in State 3, the energy consumption is significantly less than emergency heating, State 4 . The system enters into State 4 because of the low outdoor air temperature, $<28^{\circ} \mathrm{F}$. Additionally, the outdoor air temperature dependent power consumption of State 3 can be seen in Fig. 5, where the power consumed by heat pump varies as the outside air temperature varies. Energy consumption is not temperature dependent in State 4 because the heat is provided by the auxiliary resistive heating coils, the power draw of which is only dependent upon the terminal voltage, $V_{T}$.

The correlation between outdoor air temperature, the heat pump state, and the heat pump power consumption can be clearly seen in Figs. 3-5. In the simulation of a large distribution feeder, there would be hundreds or thousands of individual houses, each with an energy consumption profile similar to 


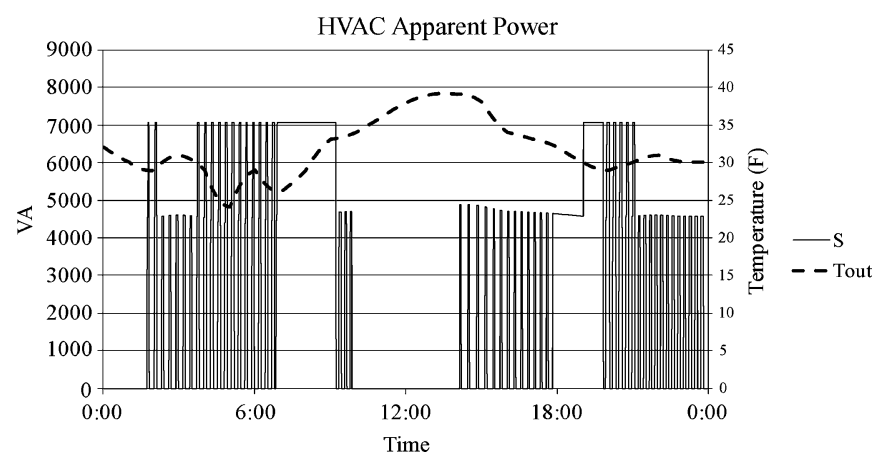

Fig. 5. House apparent power consumption with physical model.

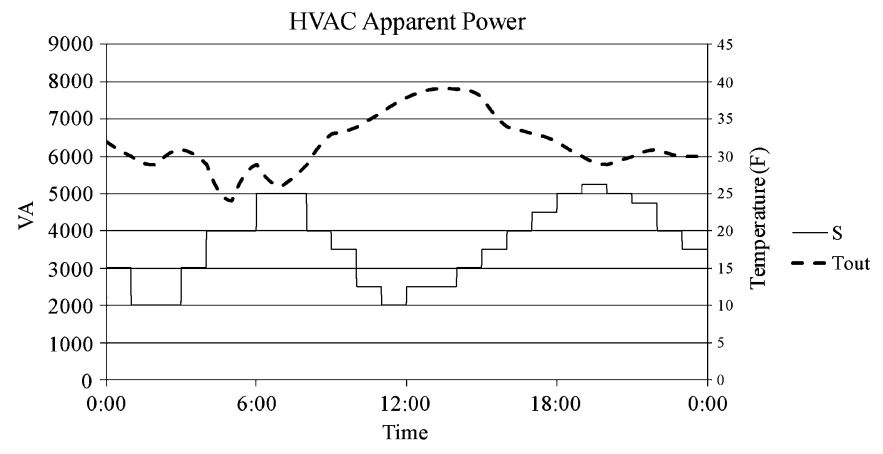

Fig. 6. House apparent power consumption with ZIP model.

that in Fig. 5. While the energy consumption profiles would be similar, variations would arise because of different thermostat set points and varying building parameters. In contrast, traditional ZIP models would apply the same values to every house without regard to temperature, and the apparent power consumption of each house would look similar to that shown in Fig. 6.

From Fig. 6, it can be seen that the ZIP model for an individual house is an approximate average of all houses and is temperature independent. Additionally, the complexities associated with determining the transitions between states in a physical model introduce a level of detail that is not possible with a simple time-variant ZIP model. For example, ZIP models are not able to simulate the occurrence of coincidental peaks between multiple heat pumps unless their occurrence is known a priori. As a result, when conducting analysis on a utility size distribution feeder, it is necessary to use a combination of time-variant ZIP models and multi-state physical models to properly represent the end-use load behavior in a time-series simulation. The next section will examine the simulation of a large-scale distribution feeder with numerous end-use loads that are composed of ZIP models and multi-state physical models.

\section{8500-Node Test System SimUlation Results}

The 8500-node test system was first presented in [23]-[25] and is available on the web site for the IEEE PES Distribution Test Feeder Working Group [3]. This test system was designed to test algorithms and simulation methodologies on a system that was sufficiently large to represent typical distribution feeders. It will be used to examine the effects of ZIP models and multi-state physical models on the analysis of a distribution

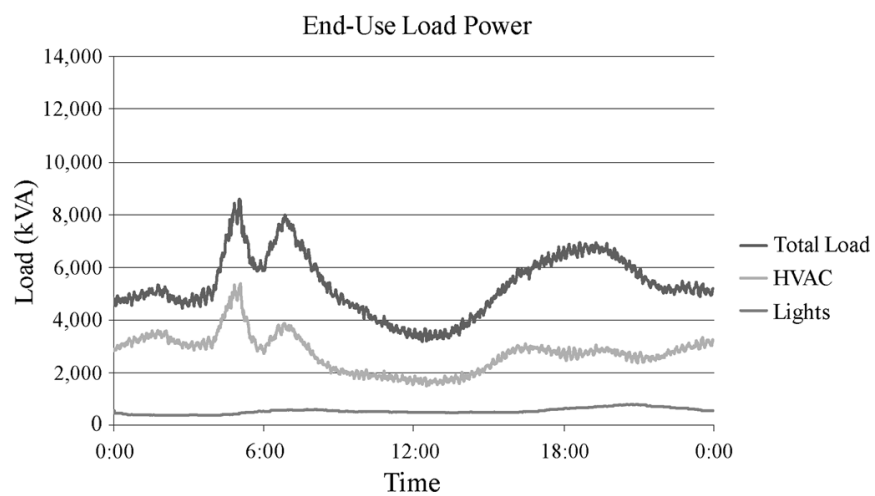

Fig. 7. Case 2 end-use load consumption.

feeder. Specifically, the 8500-node test system will be used to examine the occurrence of coincidental loads, which arise because of external driving signals such as outside air temperature.

As presented in [3], the 8500-node test system is a traditional time-invariant peak load power flow example. To examine the impacts of using time-variant ZIP models and multi-state physical load models, the time-invariant constant power loads associated with the 8500-node test system were replaced with time-variant ZIP models and physical models representing 1220 single family residences. Each residence contains a multi-state physical model for the heat pump and hot water heating. Additionally, time-variant ZIP models were included for incandescent lighting, compact fluorescent lighting, liquid crystal display televisions, ventilation fans, and miscellaneous plug loads [26]. While there are additional loads that could be included, the existing subset is sufficient to show the impacts of multi-state load models. Additionally, while it is not common for a distribution feeder to be purely residential, all with similar heat pumps, this simplification is made to highlight the impact of multi-state models.

The following sections present three cases. The first two will utilize a combination of ZIP models and physical models, while the last will utilize only ZIP models. This comparison will show that by using the multi-state physical models, the effects of varying outside air temperature can be examined, which is not be possible when only ZIP models are used.

\section{A. 8500-Node Test System (Case 2)}

Fig. 7 shows the apparent power load for the 8500-node test system, as measured at the output of the substation tap changer, over a 24-h period using weather data for a cool winter day in Seattle, Washington. In addition to total feeder loading, aggregate load levels for residential lighting, as well as the residential HVAC systems, are shown. The lighting load is modeled as a time-variant ZIP model, while the HVAC systems are modeled as heat pumps with multi-state physical models.

From Fig. 7, it can be seen that ZIP loads such as lighting have a very smooth profile, while multi-state physical models such as heat pumps have a much more irregular profile with coincident peaks that are affected by outside air temperature. To explain the load peaks, it is necessary to look at the population distribution of the heat pumps and their operational states. Fig. 8 shows the heat pump population trends for Case 2. Initially there 


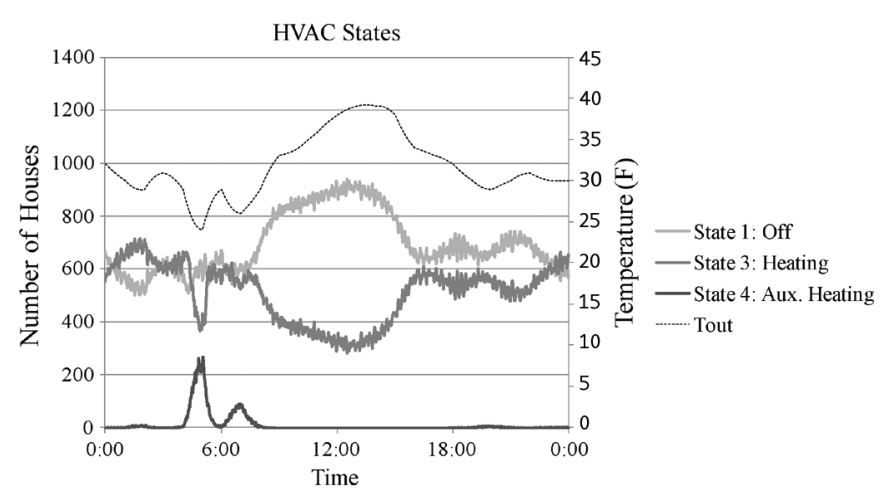

Fig. 8. Case 2 heat pump population statistics.

are approximately 650 heat pumps in State 1,570 heat pumps in State 3, and no heat pumps in State 4. As the outside air temperature drops below $T_{\text {aux }}$, approximately $28^{\circ} \mathrm{F}$, many of the heat pumps that were in State 3 begin to transition to State 4. As an individual heat pump transitions from State 3 to State 4, the energy consumption increases significantly, as seen in Fig. 5. As multiple heat pumps make the state transition, the population of units in State 3 decreases while the population of units in State 4 increases. This change in the state population results in a significant increase in load because of the difference in energy consumption between the two states, as defined in (8) and (9).

The heat pumps do not all transition from State 3 to State 4 at the same time because the $T_{a u x}$ set points for the 1220 heat pumps follow a normal distribution with a mean of $28^{\circ} \mathrm{F}$ and a standard deviation of $1^{\circ}$. This type of distribution is common in appliances where it is not necessary to calibrate internal control parameters to high levels of accuracy.

Between approximately 5:00 a.m. and 9:00 a.m., the outside air temperature experiences a "double dip", where there is a slight warming followed by a subsequent lowering of temperature. The double dip occurs around the temperature set point for the transition between States 3 and 4. As a result, there are two time periods where a portion of the heat pump population transitions from State 3 to State 4, resulting in an increase in the energy consumption. As a consequence of these transitions, there is a "double peak" in energy consumption which coincides with the double dip in outside air temperature.

It is through the use of multi-state physical load models that changes in the input parameters can be translated into changes in the state populations, and therefore the system load. In particular, the use of multi-state physical load models allows for the examination of coincidental peaks, in this case coincidental heat pump peaks. The next case will examine the impact on energy consumption when the outside air temperature profile is slightly changed.

\section{B. 8500-Node Test System (Case 3)}

In this third case, the 8500-node test system is examined with an outside air temperature that is modified from that used in Cases 1 and 2. Fig. 9 shows the outside air temperature profile from Cases 1 and 2, compared to the outside air temperature used in Case 3. For Case 3, the outside air temperature is similar

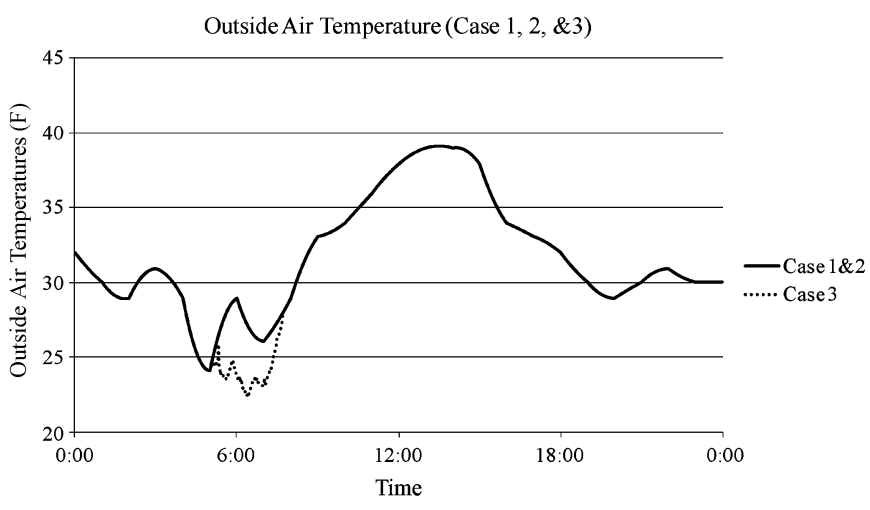

Fig. 9. Outside air temperature for Cases 1, 2, and 3.

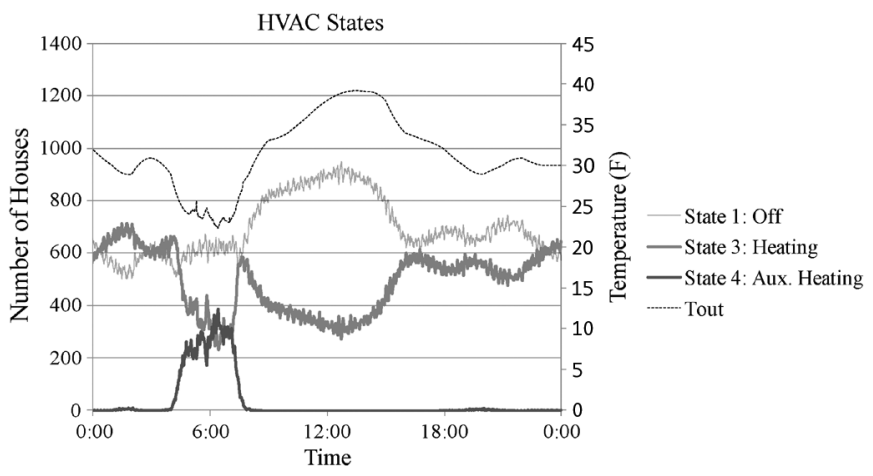

Fig. 10. Case 3 heat pump population statistics.

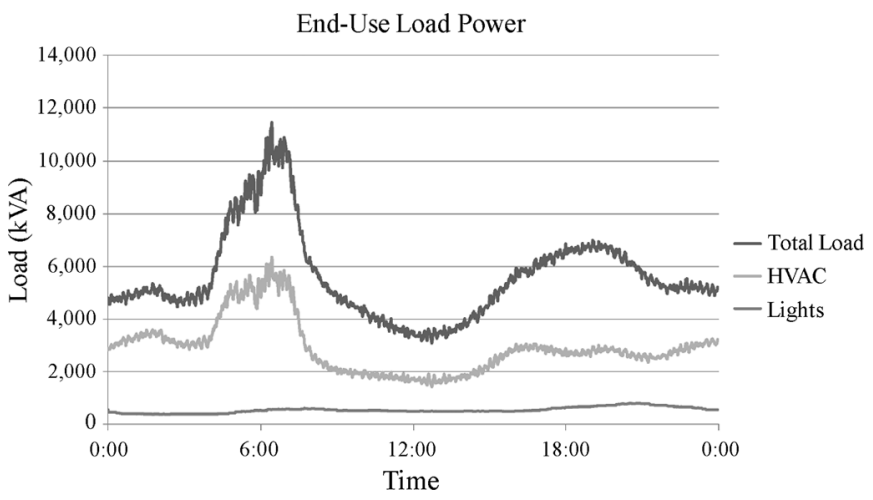

Fig. 11. Case 3 end-use load power.

to Cases 1 and 2 except that the morning low temperature is persistent from 5:00 a.m. to 9:00 a.m.; there is no double dip.

The result of the persistent low temperature in the morning can be seen in Figs. 10 and 11. Because of the continuous temperature below the nominal value of $T_{a u x}$, a larger portion of the heat pump population transitions into State 4, as seen in Fig. 10. At the peak, there are nearly 400 heat pumps operating in State 4, compared to the 275 units in Case 2. Additionally, the increase in the number of units in State 4 is persistent over the period where the temperature is below $T_{a u x}$. The result is a significantly higher peak load, which persists for a longer period of time, as seen by comparing Figs. 7 and 11, and shown in Fig. 12.

\section{8500-Node Test System (Case 4)}

In contrast to Cases 1, 2, and 3 the fourth case examines a simulation with only ZIP models. This case uses the same 


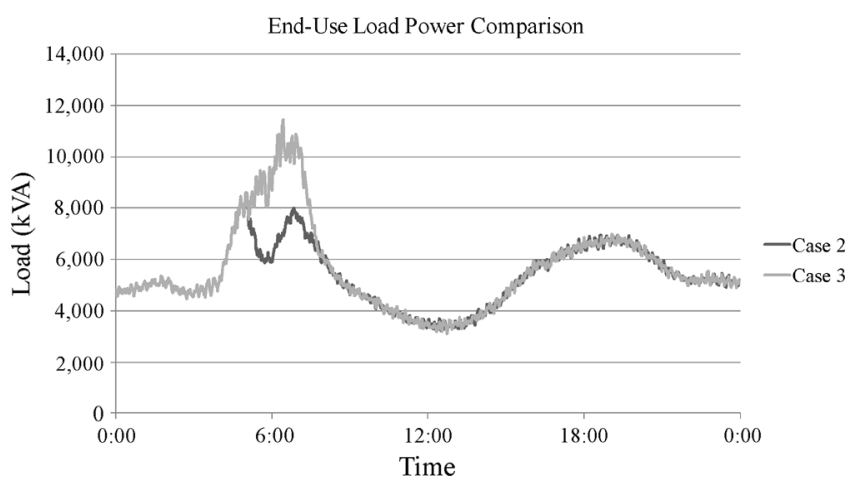

Fig. 12. Comparison of Case 2 and Case 3 end-use load power.

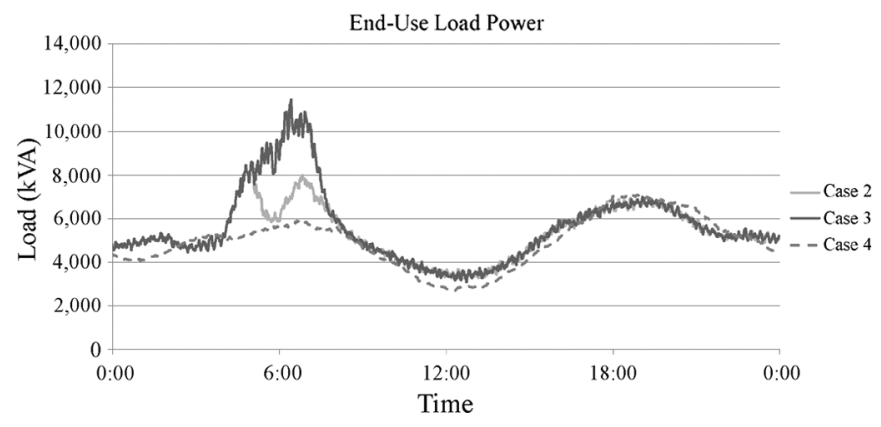

Fig. 13. Comparison of Case 2, Case 3, and Case 4 end-use load power.

8500-node test system of Cases 2 and 3 except that the physical models have been replaced with time-variant ZIP models. Fig. 13 shows a comparison of Case 2, Case 3, and Case 4, where Case 4 is a simulation using only ZIP loads.

From Fig. 13, it can be seen that the simulation results from Case 4 approximate the general load level and energy consumption, but it does not capture the large temperature deviation, and subsequent coincidental load peak. Simulating coincidental peaks that occur as a result of an external signal, in this case outside air temperature, cannot be done with purely time-variant ZIP models. In Cases 2 and 3, the use of multi-state physical load models allows for the impact of temperature variations to be translated into variations in energy consumption and instantaneous demand; Case 4 was not able to differentiate between the temperature signals because of the exclusive use of ZIP load models.

\section{CONCLUSIONS}

In this paper, it is shown that the use of multi-state physical load models can be used to properly represent the behavior of end-use loads. In particular, it is shown that varying external air temperature impacts the load on a distribution feeder in ways that cannot be represented using conventional ZIP load models. By using the multi-state physical load models, it is shown that the population distribution of loads can be tracked and that variations in the population distributions can be translated into energy consumption.

While external air temperature is used as the control signal in this paper, the same multi-state physical load models could be used to analyze many of the emerging smart grid technologies, which use other external control signals such as price and frequency to modify the natural behavior of the end-use loads. Unless appropriate end-use load models such as time-variant ZIP models and multi-state physical models are implemented, it is not possible to accurately model many of the emerging technologies, or to determine their true impact on distribution system operations.

While this paper identifies multi-state physical load models that are appropriate for research use, future work will focus on developing reduced order models that can be used by utilities. Understanding the detailed operation of end-use loads makes it possible to determine which simplifications are appropriate and how best to represent the behavior of end-use loads, without continually solving coupled differential equations during the simulation. This will allow for analysis of the emerging generation of technologies to be conducted by a broad range of stakeholders.

\section{REFERENCES}

[1] W. H. Kersting, Distribution System Modeling and Analysis, 2nd ed. New York: CRC, 2007.

[2] N. Samaan, T. McDermott, B. Zavadil, and J. Li, "Induction machine test case for the 34-bus test feeder-Steady state and dynamic solutions," in Proc. 2006 IEEE PES General Meeting, pp. 1-5.

[3] IEEE PES Distribution Systems Analysis Subcommittee Radial Test Feeders. [Online]. Available: http://www.ewh.ieee.org/soc/pes/ dsacom/testfeeders.html.

[4] R. C. Dugan, W. H. Kersting, S. Carneiro, Jr., R. F. Arritt, and T. E. McDermott, "Roadmap for the IEEE PES test feeders," in Proc. 2009 IEEE PES Power Systems Conf. Exhib., pp. 1-4.

[5] J. R. Carson, "Wave propagations in overhead wires with ground return," Bell Syst. Tech. J., vol. 5, p. 539, 1926.

[6] P. A. N. Garcia, J. L. R. Pereira, S. Carneiro, Jr., V. M. Da Costa, and N. Martins, "Three-phase power flow calculations using the current injection method," IEEE Trans. Power Syst., vol. 15, no. 2, pp. 508-514, May 2000.

[7] L. R. Araujo, D. R. R. Penido, S. Carneiro, J. L. R. Pereira, and P. A. N. Garcia, "A comparative study on the performance of TCIM full newton versus backward-forward power flow methods for large distribution systems," in Proc. 2006 IEEE PES Power Systems Conf. Expo., pp. 522-526.

[8] W. G. Sunderman, R. Dugan, and D. Dorr, "The neutral-to-earth voltage (NEV) test case and distribution system analysis," in Proc. 2008 IEEE PES Transmission and Distribution Conf. Expo., pp. 1-7.

[9] D. R. R. Penido, L. R. Araujo, S. Carneiro, Jr., and J. L. R. Pereira, "Solving the NEV test case using the current injection full-newton power flow," in Proc. 2008 IEEE PES Transmission and Distribution Conf. Expo., pp. 1-7.

[10] SynerGEE Electric. [Online]. Available: http://www.gl-group.com.

[11] WindMil. [Online]. Available: http://www.milsoft.com.

[12] Cymdist. [Online]. Available: http://www.cyme.com.

[13] D. Kosterev, A. Meklin, J. Undrill, B. Lesieutre, W. Price, D. Chassin, P. Bravo, and S. Yang, "Load modeling in power system studies: WECC progress update," in Proc. 2008 IEEE PES General Meeting, pp. 1-8.

[14] R. T. Guttromson, D. P. Chassin, and S. E. Widergren, "Residential energy resource models for distribution feeder simulation," in Proc. IEEE Power Eng. Soc. General Meeting, Jul. 13-17, 2003, vol. 1, p. 113.

[15] K. Schneider and J. Fuller, "Detailed end-use models for distribution system analysis," in Proc. 2010 IEEE PES General Meeting, pp. 1-7.

[16] R. Sonderegger, "Dynamic models of house heating based on equivalent thermal parameters," Ph.D. dissertation, Center for Environmental Studies, Princeton Univ., Princeton, NJ, 1978.

[17] K. Subbarao, Thermal Parameters for Single and Multizone Buildings and Their Determination From Performance Data, Solar Energy Research Institute. Golden, CO, 1981.

[18] N. W. Wilson, B. S. Wagner, and W. G. Colborne, "Equivalent thermal parameters for an occupied gas-heated house," ASHRAE Trans., vol. 91 , pt. 2, pp. 1875-1884, 1985. 
[19] R. G. Pratt and Z. T. Taylor, Development and Testing of an Equivalent Thermal Parameter Model of Commercial Buildings From Time-Series End-Use Data, Pacific Northwest Laboratory. Richland, WA, 1990.

[20] M. A. El-Sharkawi, Fundamentals of Electric Drives. Pacific Grove, CA: Brooks/Cole, 2000

[21] T. Wildi, Electric Machines, Drives, and Power Systems, 4th ed. Upper Saddle River, NJ: Prentice-Hall, 2000.

[22] GridLAB-D. [Online]. Available: http://www.gridlabd.org.

[23] R. F. Arritt and R. C. Dugan, "The IEEE 8500-node test feeder," in Proc. 2010 IEEE PES Transmission and Distribution Conf. Expo., pp. 1-6.

[24] K. Schneider and J. Fuller, "Voltage control devices on the IEEE 8500 node test feeder," in Proc. 2010 IEEE PES Transmission and Distribution Conf. Expo., pp. 1-6.

[25] D. Penido, L. De Araujo, S. Carneiro, Jr., and J. Pereira, "Load-flow analysis of the IEEE 8500 node test case using the current injection method," in Proc. 2010 IEEE PES Transmission and Distribution Conf. Expo., pp. 1-6.

[26] K. Schneider, J. Fuller, F. Tuffner, and R. Singh, Evaluation of Conservation Voltage Reduction on a National Level PNNL-19596, Pacific Northwest Laboratory. Richland, WA, 2010.

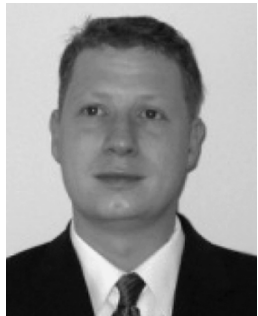

Kevin P. Schneider (M'06-SM'08) received the B.S. degree in physics and the M.S. and Ph.D. degrees in electrical engineering from the University of Washington, Seattle.

His main areas of research are distribution system analysis and power system operations. He is currently a research engineer at the Pacific Northwest National Laboratory, working at the Battelle Seattle Research Center in Seattle. He is an Adjunct Faculty member at the Washington State University, Pullman, and an Affiliate Assistant Professor at the University of Washington.

Dr. Schneider currently serves as the Vice-Chair for the Seattle Power Engineering Society section and as Vice-Chair for the IEEE Distribution System Analysis Sub-Committee. He is a licensed Professional Engineer in Washington State.

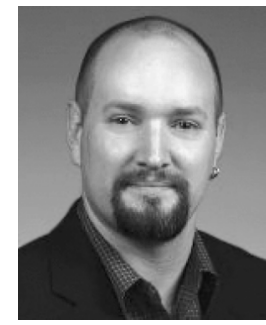

Jason C. Fuller (S'08-M'10) received the B.S. degree in physics from the University of Washington, Seattle, and the M.S. degree in electric engineering from Washington State University, Pullman.

$\mathrm{He}$ is currently a research engineer at the Pacific Northwest National Laboratory. His main areas of interest are distribution system analysis and renewable integration. He is currently the Secretary of the Distribution System Analysis Subcommittee's Test Feeder Working Group.

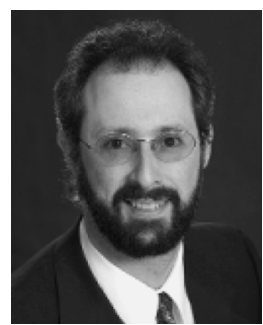

David P. Chassin (M'03-SM'05) received the B.S. degree in building science from Rensselaer Polytechnic Institute, Troy, NY.

He is a staff scientist with the Energy Science and Technology Division at Pacific Northwest National Laboratory, where he has worked since 1992 . He was Vice-President of Development for Image Systems Technology from 1987 to 1992, where he pioneered a hybrid raster/vector computer aided design (CAD) technology called CAD Overlay. He has experience in the development of building energy simulation and diagnostic systems, leading the development of Softdesk Energy and DOE's Whole Building Diagnostician. His recent research focuses on emerging theories of complexity as they relate to high-performance simulation and modeling in building controls and power systems and is currently responsible for the design and development of DOE's GridLAB-D simulator. 